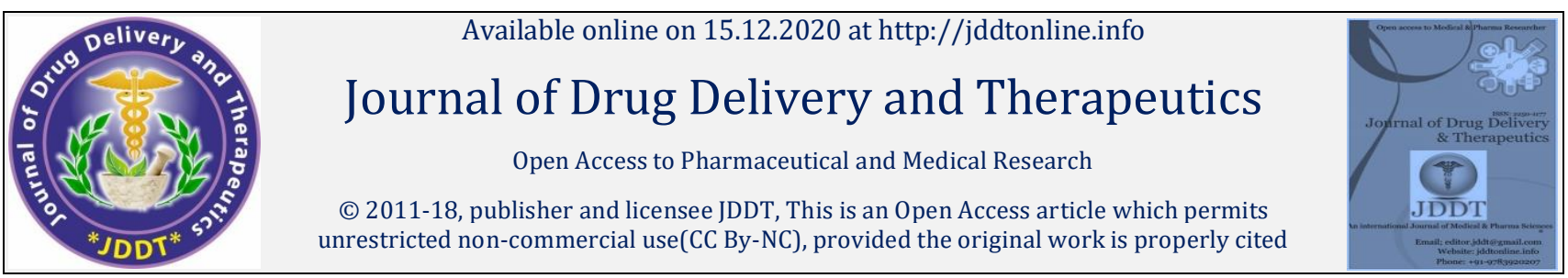

Open $\odot$ Access

Review Article

\title{
As Review on Microsponge Gel as Topical Drug Delivery System
}

\author{
Kshatriya Pravin Jamnadas ${ }^{1}$, Shinde Jitendra V. ${ }^{1}$, Chavan Rajashree S. ${ }^{2}$ \\ 1 Department of Pharmaceutics, PDEA's S.G.R.S. College of Pharmacy, Saswad, India \\ 2 Pune District Education Association's Seth Govind Ragunath Sable College of Pharmacy, Saswad, Pune, Maharashtra, India
}

\begin{abstract}
Microsponges are drug delivery systems composed of porous microspheres. They are little sponge - like spherical particles with an outside surface porous surface. Moreover, they will enhance stability, scale back aspect effect and modify drug unharness favourably. Microsponge technology has several favorable characteristics that make it a flexible drug delivery vehicle. Microsponge system square measure supported microscopic, chemical compound based mostly microspheres that may suspend or entrap a good type of substances, and might may be incorporated into a developed product like a gel, cream, liquid, powder. The outer surface is often porous, permeating a sust ained flow of drugs out of sphere. Microsponges square measure porous, compound microspheres that square measure used principally for typical use and have recently been used for oral administration. microsponge square measure designed to deliver a pharmaceutical active ingredient with efficiency at the minimum dose and additionally to reinforce solubility, scale back aspect effects and modify drug unharness.
\end{abstract}

Kyewords: Controlled release, drug delivery, care systems, microponges.

Article Info: Received 03 Oct 2020; Review Completed 21 Nov 2020; $\quad$ Accepted 29 Nov 2020; Available online 15 Dec 2020

Cite this article as:

Kshatriya PJ, Shinde JV, Chavan RS, As Review on Microsponge Gel as Topical Drug Delivery System, Journal of Drug Delivery and Therapeutics. 2020; 10(6-s):125-133ｈttp://dx.doi.org/10.22270/jddt.v10i6-s.4455

*Address for Correspondence:

Kshatriya Pravin Jamnadas, Department of Pharmaceutics, PDEA's S.G.R.S. College of Pharmacy, Saswad, India

\section{INTRODUCTION:}

In recent years, there has been right smart stress given to the event of novel microsponge base drug delivery systems, so as to change and management the discharge behavior of medication. By incorporation into a carrier system, it's doable to change the therapeutics index and length of the activity of medication. The ever-increasing interest among shoppers with relevance skin care and skin treatment merchandise has been fostered by the widespread use of ingredients like $\alpha$-chemical group acid and vitamins in topical merchandise, which might induce perceivable and demonstrable edges- particularly in aging or image broken skin. Though quite helpful, in several instances, these ingredients might turn out irritancy; such irritancy is perceived as burning, stinging or redness and notably happens in people with sensitive skin. Recognizing this drawback, the formulators have tried to traumatize drawback in one in all two stratergies. They need reduced the concentration of such ingredients, however within the method, sacrified effectuality. They need additionally changed the vehicles so as to create the merchandise additional empllients or skin- compatible. 1 But this approach, in several cases, additionally reduces the useful effects of ultimate product. The increasing arena of rising medicine, magnified sensitivity to clinical outcomes, and care prices are driving the requirement for different drug delivery strategies and devices. Drug delivery systems that may exactly management the discharge rates or target medicine to a selected body website have had a vast impact on the care system. Many predictable and reliable systems been developed for general medicine underneath the heading of percutaneous drug delivery systems (TDS) mistreatment the skin as a portal of entry. ${ }^{2}$ it's improved the effectuality and safety of the many medicine that will be higher administered through skin. However, TDS isn't sensible for delivery of materials whose final target is that the skin itself. Controlled unharness of drug onto stratum with associate assurance that the drug remains primarily localized and doesn't enter the circulation in important amounts, is a locality of analysis that has solely recently been addressed successfully. No economical vehicles are developed for controlled and localized delivery of medication into horny layer and underlying skin layer and not on the far side the stratum. Moreover, the applying of topical medicine has several issues, such as, ointments that are typically esthetically unappealing, greasiness, stickiness, and so on, that always leads to lack of patient compliance. These vehicles need a high concentration of active agents for effective medical aid owing to their low potency of delivery system, leading to 
irritation and hypersensitivity in important users. Different drawbacks of topical formulations and uncontrolled evaporation of active ingredient, unpleasant odor, and also the potential incompatibility of the medicine with the vehicles. Typical formulations of medicine are meant to figure on the outer layers of the skin. Typically, such merchandise unharness their active ingredients upon application, manufacturing extremely targeted layer of active ingredients that's apace absorbed. Therefore the requirement exists for a system to maximize the quantity of your time that an energetic ingredients is gift either on the skin surface or inside the stratum, whereas minimizing its percutaneous penetration into the body. Microsponges are microscopic spheres capable of engrossing skin secretions, therefor reducing oiliness and shine from the skin. Spherical particles composed of clusters of even tinier sphere are capable of holding fourfold their weight in skin secretions. Microsponge particles are very little, inert, indestructible spheres that don't meet up with the skin. Rather, they collect within the small nooks and crannies of the skin and slowly unhaeness the entrapped drug, because the skin desires it. The microsponge system will stop excessive accumulation of ingredients inside the stratum and also the stratum. Doubtless, the microsponge system will considerably scale back the irritation of effective drug while not reducing their effectuality. The empty spheres are then washed away with subsequent cleansing. The microsponge system fulfills these needs and has resulted in new generation of terribly welltolerated and extremely efficacious, novel merchandise. These merchandise are usually conferred to the patron in typical forms like creams, gel or lotions and that they contain a comparatively high concentration of active ingredients. Microsponge area unit proprietary compound delivery systems consisting of porous microsphere which will entrap a good vary of active ingredients like emollients, fragrances, volatile oil, sunscreens, and anti-infective, anti-fungal, and anti-inflammatory agents. ${ }^{3}$ sort of a true sponge, every microsphere consists of a myriad of inter connecting voids among a non-collapsible structure, with an outsized porous surface. The microsponge technology was developed by won in 1987, and also the original patents were allotted to advanced chemical compound systems, Inc. ${ }^{4}$ This company developed an outsized variety of variations of the technique and applied those to the cosmetic still as over-the-counter [OTC] and prescription pharmaceutical product. At this time, this attention grabbing technology has been accredited to cardinal health, Inc., to be used in topical product the scale of microsponges may be varied, typically from $5-300 \mu \mathrm{m}$ in diameter, relying upon the degree of smoothness or afterfeel needed for the top formula. Though the microsponge size could vary, a typical $25 \mu \mathrm{m}$ sphere will have upto 250000 pores associate degreed an internal pore structure such as ten foot long, providing a complete pore volume of regarding $1 \mathrm{ml} / \mathrm{g}$. this leads to an outsized reservoir among every microsponge, which may be loaded with up to its own weight of chemical agent. The microsponge particles themselves live large to be absorbed into the skin and this adds a measure of safety to those microsponge materials. Another safety concern is that the potential microorganism contamination of the materials entrapped within the microsponge. Because the size of the pore diameter is smaller, the microorganism starting from 0.007 to $0.2 \mu \mathrm{m}$ cannot penetrate into the tunnel structure of the microsponges.

\section{ADVANTAGES OF MICROSPONGE}

$>$ Microsponge systems are non- irritating, nonmutagenic, non-allergenic and non-toxic.

$>$ Improved formulation flexibility.

$>$ Extended release of drug continuous up to 12 hours.

$>$ Reduce irritation and improve patient compliance.

$>$ Microsponge drug delivery can improve bioavailability of drug.

$>$ They have better thermal, physical and chemical stability.

$>$ Allows incorporation of immiscible product.

$>$ Advance oil control.

$>$ Easy to formulate.

\section{LIMITATION OF MICROSPONGE}

$>$ The preparation methods usually use organic solvents as paragons, which pose an environmental hazard, as some may be highly inflammable, posing a safety hazard.

$>$ In some cases, the traces of residual monomer have been observed, which may be toxic and hazardous to health.

\section{APPLICATION OF MICROSPONGE}

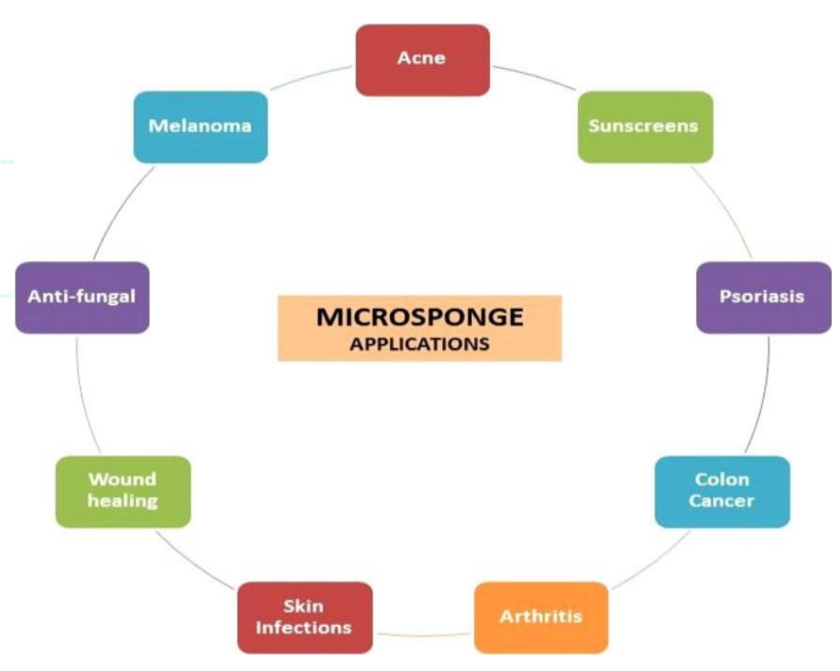


RELEASE MECHANISM OF MICROSPONGES:-

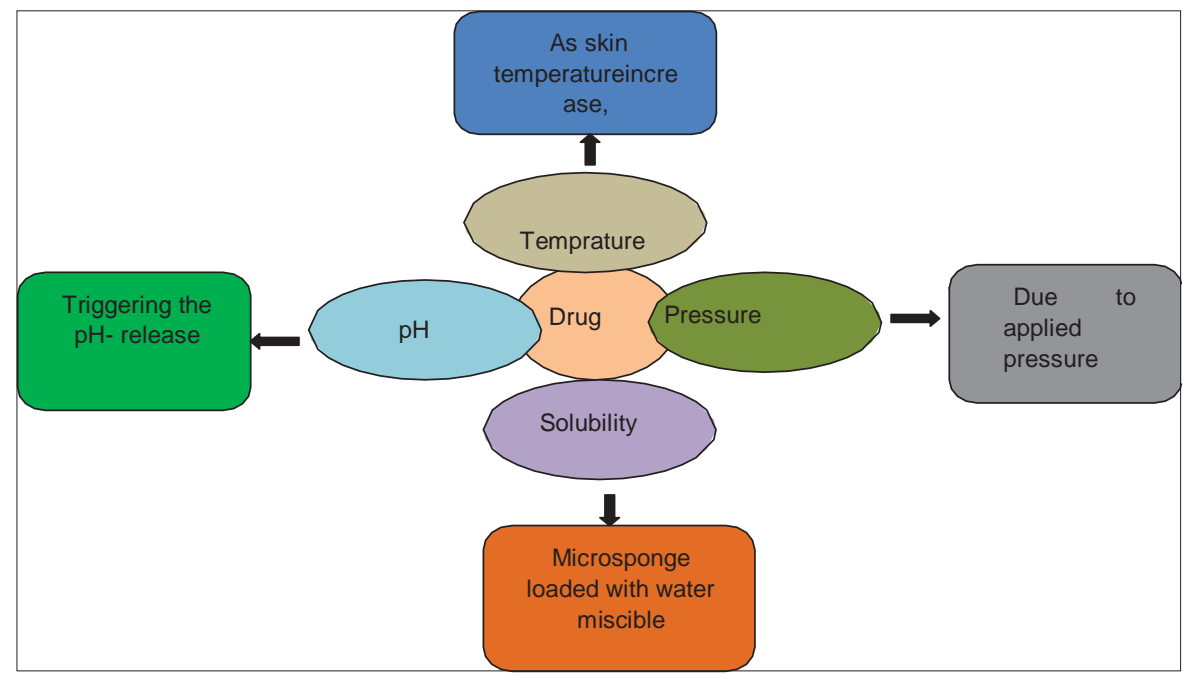

METHOD OF PREPARATION:
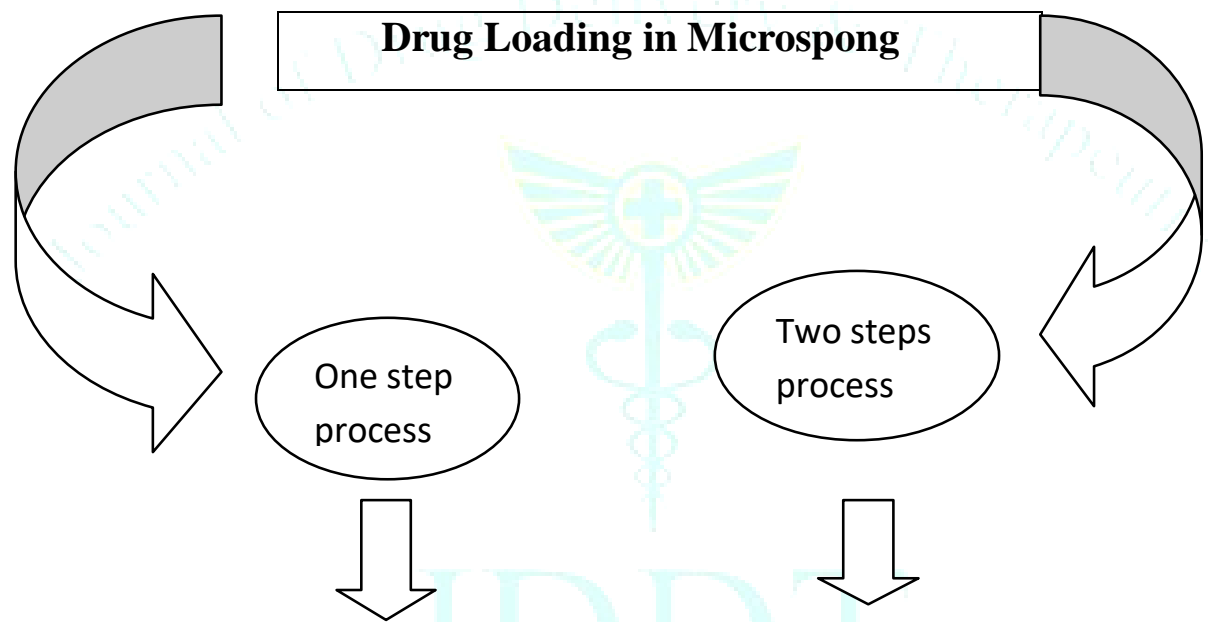

Liquid - Liquid Suspension Polymerization

Quasi - Emulsion Solvent Diffusion

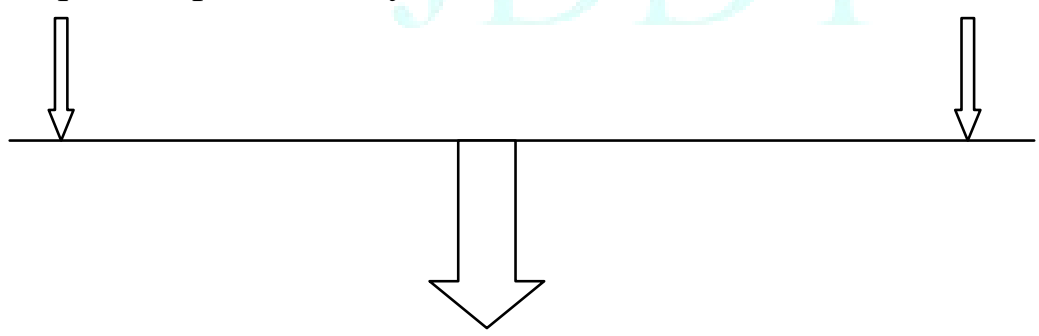

Based on Physico-Chemical Properties of Drug to be loaded

\section{Liquid-Liquid suspension chemical process 24-26}

In this vehicle of chemical process, the monomers area unit dissolved beside the active ingredients, i.e., water in appropriate solvent followed by addition of additives, suspending agent area unit additional to the formation of suspension. The chemical process is like initiated by adding catalyst porous. Once the chemical \{process| chemical change| chemical action\} process the solvent is removed deed the spherical porous structure microsponge. 


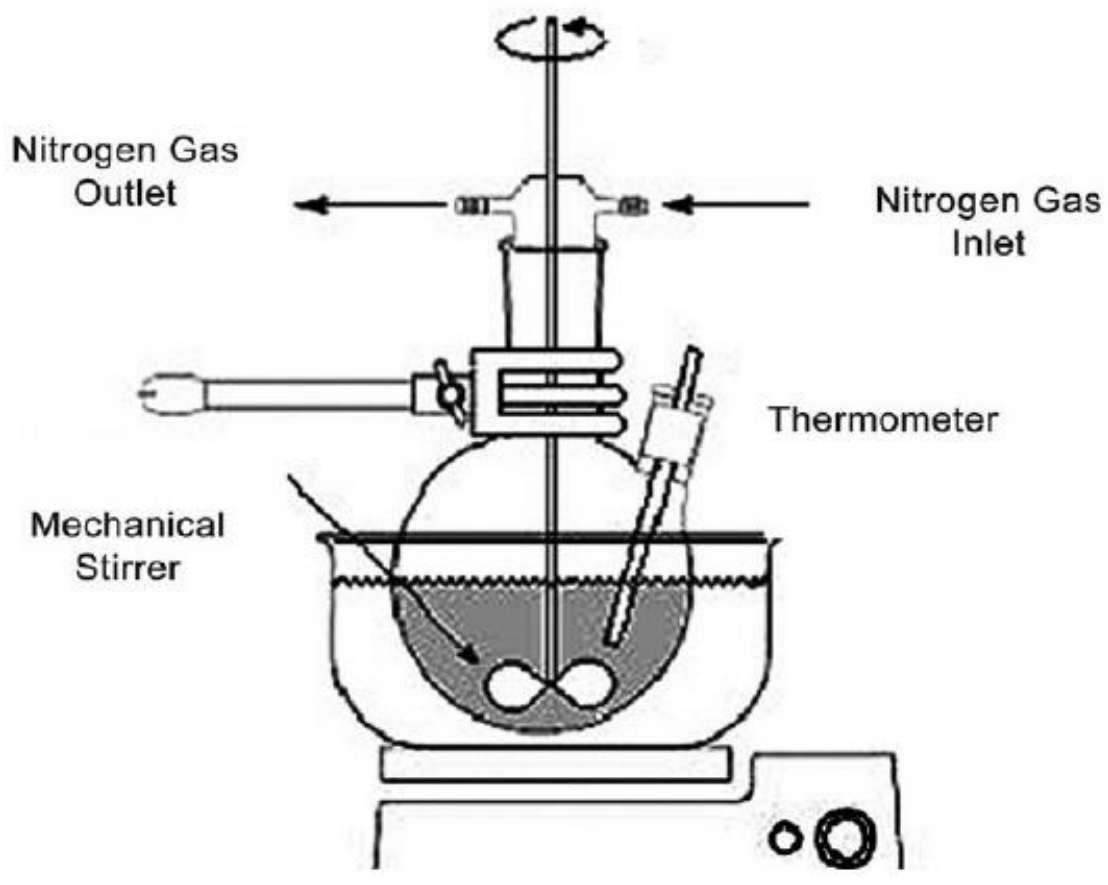

Figure 1: Liquid - Liquid Suspension Chemical Method.

\section{Quasi-emulsion solvent diffusion 27-29}

Microsponge may be ready by quasi-emulsion solvent diffusion methodology exploitation the various compound amounts to arrange the inner organic part, compound dissolved in appropriate solvent followed by addition drug dissolved beneath ultra - sonication at $35^{\circ} \mathrm{C}$ This resolution created inner part. The inner part is poured into the outer part (polyvinyl alcohol resolution in water). Once stirring, the mixture is filtered to separate the developed microsponges. The microsponges area unit dried in associate air heated kitchen appliance at a temperature that is compatible for compound.

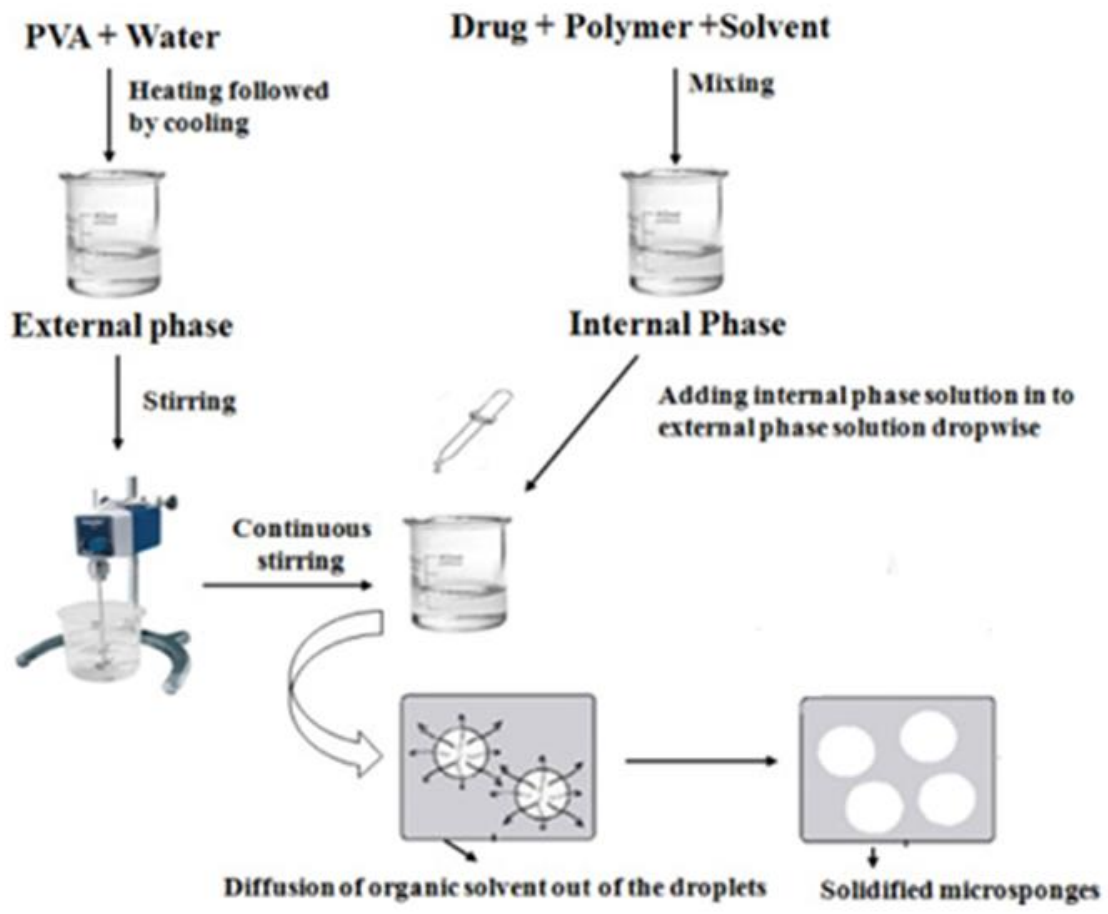

Figure 2: Quasi - Emulsion Solvent Diffusion Method 
List of instruments

\begin{tabular}{|c|c|c|}
\hline Sr. no. & Instruments & Manufacturer \\
\hline 1 & Single pan electronic balance & Schimadzu crp. Model (ATX224) \\
\hline 2 & Infrared spectrophotometer & FTIR- schimadzu \\
\hline 3 & Ultrasonicator & Wensar electronics Pvt. Ltd. ,Mumbai \\
\hline 4 & Mechanical stirrer & Remi equipments ltd., Mumbai \\
\hline 5 & Magnetic stirrer & Remi equipments ltd., Mumbai \\
\hline 6 & UV Spectrophotometer. & Dynamica model :halo DB20 \\
\hline 7 & Differential scanning calorimeter & Mettle- Toledo DSC 82 le, Switzerland. \\
\hline 8 & Brook field viscometer & LVDV-E Brook fieid viscometer, Eng. Lab, USA. \\
\hline 9 & Diffusion cell digital & Fabricated apparatus \\
\hline 10 & Digital potentiometer motic digital microscope & Equiptronics model ( EQ-601) \\
\hline 11 & Motic digital microscope & B1 Advanced series. \\
\hline 12 & Hot air oven & Biotechnics india. \\
\hline 13 & Dissolution test apparatus & Electrolab (TDT)-08LUSP Type I \\
\hline
\end{tabular}

\section{EVALUATION OF MICROSPONGE}

\section{Preformulation Study}

Preformulation parameters area unit designed to spot those chemical science properties, freezing point, and excipients that will have an effect on the formulation style, methodology of manufacture, pharmacokinetics and biopharmaceutical properties. Organoleptic property as a chemical state, taste, odor and color of the drug area unit studied out 37

Identification and drug - chemical compound compatibility

Differential scanning measuring system (DSC) analysis DSC analysis area unit meted out to verify compatibility and thermal behavior of medication, physical mixture of medication, chemical compound and their formulation.

\section{Fourier remodel infrared spectroscopic analysis (FTIR)}

Identification of purposeful teams gift in pure drug, physical mixture of drug, and chemical compound area unit interpretated by FTIR prism spectroscope. The result showed that no chemical interaction or changes manifest itself throughout the preparation of formulation, and also the drug was found to be stable 39

\section{Particle size analysis of microsponge}

Particle sizes of the microsponge area unit meted out by optical maser light-weight diffractometry, optical research the other applicable methodology.

Analysis of morphology and surface topography of microsponges. The presence of pores is an important feature of microponges, its internal and external morphology and surface topography will be obtained by mistreatment SEM and transmission microscopy (TEM). The particle size, form and surface morphology examined by SEM and TEM found porous, spherical form in $\mu$ m size 41 .

\section{Analysis of pore structure}

The rate of drug unharness from microsponges will impact by diameter of microsponges. Many consistence parameters of microsponges like total extent, intrusion-extrusion isotherms, pore size, distribute, average pore size diameters, form and morphology of the pores, bulk and apparent density also are be analyzed 42 .

Determination of loading efficiency and production yield 43

The loading efficiency (\%) is calculated using the following equation:

Actual drug content in microsponges

Loading efficiency $=\overline{\text { Theoretical dug content }}$ $\times 100$

The production of microparticles will analyzed by calculative accurately the initial weight of the raw material and also the final weight of microsponge obtained.

\section{Production Yield:}

Production yield $=\frac{\text { Particle mass of microsponges }}{\text { Theoretical mass [polymer a drug] }} \times 100$

\section{In vitro dissolution analysis:}

Dissolution profile of microsponges square measure studied by dissolution equipment USPXXIII with a changed basket consisted of five chrome steel mesh and therefore the speed of rotation $100 \mathrm{rpm}$ and temperature of $37 \pm 0.5^{\circ} \mathrm{C}$ was maintained throughout the experiment. Whereas considering solubility of active guarantee sink conditions. At mounted intervals, aliquots were withdrawn and replaced with contemporary dissolution medium. Samples from the dissolution medium will be analyzed by actinic radiation photometer at numerous $\mathrm{nm}$ at numerous intervals. The concentrations of drug free at totally different time intervals make up my mind by measurement absorbance 45

\section{Motic Digital Resaerch}

For morphology and surface topography, ready microsponges will be placed on a glass slide at temperature so the surface morphology of the microsponges will be studied by motic digital research (B1 advanced series). Motic digital research of a broken microsponge particle also can be taken as an example its ultrastructure. 11

\section{Analysis of True Density}

Ultrapycnometer is employed for determination of true density of microsponges 46 . 


\section{PATENTS FILED ASSOCIATED WITH MICROSPONGES APPROCHES 66}

Intellectual property quality (patents) is that the core of the many organization and transaction associated with technology. Licenses and assignments of belonging rights square measure common operations within the technology markets, still as providing loan security. Few patents square measure mentioned in following table associated with microsponges approach in pharmaceutical science.

Patents field related to microsponge approaches:-

\begin{tabular}{|l|l|l|l|}
\hline Sr. no. & Inventors & Publication data & Patent number \\
\hline 1 & Won & 1987 & US4690825 \\
\hline 2 & Dean et al. & 1989 & US4863856 \\
\hline 3 & Schaefer et al. & 1989 & US5292512 \\
\hline 4 & Katz et al. & 1992 & US5135740 \\
\hline 5 & Chantal et al. & 1994 & US5679374 \\
\hline 6 & Robert et al. & 1994 & US5316774 \\
\hline 7 & Ray & 1996 & US5725869 \\
\hline 8 & Straub et al. & 1999 & US63953000 \\
\hline 9 & Tomlinson et al. & 2001 & US6211250 \\
\hline 10 & Shefer et al. & 2002 & US20030232091 \\
\hline 11 & Singh & 2003 & US20030008851 \\
\hline 12 & Maurizio & 2004 & US20040247632 \\
\hline 13 & Steven et el. & 2005 & US20050271702 \\
\hline 14 & Malek & 2007 & US20070141004 \\
\hline 15 & Halliday & 2008 & US20080160065 \\
\hline 16 & Karyion Inc. & 2009 & US7604814 \\
\hline 17 & Sara Vargas & 2010 & US7740886 \\
\hline 18 & Celmatrix Corporation & 2011 & US7749489 \\
\hline 19 & Karykion Corporation & 2012 & US8323672 \\
\hline 20 & Ferring B.V & 2013 & US8361273 \\
\hline 21 & Stiefel Research Australia Pty Ltd. & 2014 & US8758728 \\
\hline 22 & Galderma Research and Development & 2015 & US8936800 \\
\hline
\end{tabular}

\section{Preparation of Microsponge Loaded Gel:}

The optimized microsponge formulation was incorporated in compound base to gels. At first needed quality of compound base further to water and unbroken long for complete association of compound chains. Microsponge dispersion was further to the hydrous compound resolution to get final concentration of drug. The ready gel was used for drug deposition study.

\section{Viscosity Measuring}

The consistency of the various gel formulation was firm employing a Brookfield viscometer. The consistency of the optimized formulation was firm while not dilution victimization Brookfield viscometer (Model-LVDV-E). Brookfield viscometer consist of a cup, that is stationary and a spindle that is rotating totally different sized rotating spindles square measure used and immersed within the check material. For liquids with low consistency, giant size spindles (large diameter and surface square measure) square measure used whereas for higher consistency liquid little spindles (small diameter and surface area) are used. Rotate the spindle within the microsponge gel until we tend to get a continuing dial reading on the show of the viscometer. This procedure is continual 3 times for duplicable results $15-16$

\section{pH Determination}

this is determined for the hydrogen ion concentration of microsponge of non-steroidal anti- inflammatory drug gel hydrogen ion concentration half-dozen. $2 \pm 0.2$ by victimization digital hydrogen ion concentration meter and therefore the reading taken for a median of three times et al., 2014, were optimized hydrogen ion concentration of microsponge of antifungal agent nitrate loaded gel was firm victimization digital hydrogen ion concentration meter result was needed by formulation hydrogen ion concentration half dozen. $7 \pm 0.06,6.8 \pm 0.06$.

\section{Stability Test:}

Stability studies of microsponge square measure studied out of varied formulation at totally different temperature and ratio. Om storing microsponge gel was evaluated 15,30 , and 45 days. Non-steroidal anti-inflammatory drug gel as per ICH pointers, on keeping at $40^{\circ} \mathrm{C}$ with $\mathrm{RH} 45 \%$ for the amount of 90-days.

\section{Rheological Charaterization:}

The microsponge gel showed creep recovery. Creep recovery check, it's shown higher creep recovery that was useful for promising gelling with higher snap. This property helps in dilution of the gel fraught with higher adherence time on the skin.

\section{Skin Irritation Test:}

Skin irritation check of optimized loaded microsponge gel was compared with the marketed and placebo gel. The microsponge is simply too giant to submit to the horny layer and it might expected to stay on the skin surface, bit by bit cathartic its contents over time. This reduces the upper exposure to the skin and make contact with amount. This was useful to scale back the irritation and toxicity of drug.

\section{In vitro drug release kinetic study}

To determine the drug unleash mechanism and to see the discharge profile variations among microsponge gel formulations, the knowledge obtained from the drug discharge amount and time were used. The drug unleash dynamics was analyzed with mathematical model like Zero 
order, First order, Higuchi model, Hixson Crowell and Korsmeyer-Peppas model. Projected to elucidate the discharge characteristics od a drug from matrix. The three parameters were accustomed study the discharge mechanism i.e. unharness rate Constant(k), correlation and unharness exponent (n) and confirm the simplest work model for optimized formulation 17 .

The discharge the knowledge was analyzed with subsequent methamatical model:-

\section{Zero Order Kinetics:}

Drug dissolution from pharmaceutical indefinite quantity forms that don't disaggregate and unharness the drug alowly (presumptuous that space doesn't amendment and no equilibrium conditions square measure obtained) will be best by the subsequent equation :

$$
\mathrm{Q}=\mathrm{K} 0 \mathrm{t}
$$

Where $Q$ letter is that the quantity of drug discharged at time $\mathrm{t}, \mathrm{K} 0$ is that the zero order rate constant expressed inunit of concentration/time and $t$ is the time in hours. The pharmaceutical indefinite quantity forms following profile, unharness an equivalent quantity of drug by a unit of your time. This model represents a perfect unharness profile so as to realize the prolonged medicine action ${ }^{17}$.

\section{First Order Kinetics;}

This model was conjointly been accustomed described absorption and / or elimination of some drug, through its tough to gestate this mechanism on a theoretical basis;

$$
\mathrm{Q} 1=\mathrm{Q} 0 \mathrm{e}-\mathrm{K} 1 \mathrm{t}
$$

Wherever Q1 is that the quantity of drug discharged in time $t, \mathrm{Q} 0$ is that the initial quantity of drug within the answer and $\mathrm{K} 1$ is that the initial order constant. The pharmaceutical indefinite quantity type following this profile, like water soluble medication in porous matrices release the drug in such some way that's proportional to the number of drug remaining in its interior, in such some way that the number of drug discharged by a unit of your time diminishes ${ }^{17}$.

\section{Higuchi Matrix Model:}

This model is employed to check the discharge of water soluble and low soluble medication incorporated in solid and/or solid matrices. Mathematical expressions were obtained for drug particles spread in a very uniform matrix behaving because the diffusion media. It describes drug unharness as a diffusion method supported the Fick's law, root time dependent ${ }^{17}$.

$$
\mathrm{Q}=\mathrm{KH} \mathrm{t} 1 / 2
$$

Where $Q$ is that the quantity of drug unharnesses in time $t$, $\mathrm{KH}$ is that the Higuchi dissolution constant.

Korsmeyer -Peppas Model:

\section{Application of Microsponge Gel}

\begin{tabular}{|l|l|}
\hline Active agents & Applications \\
\hline Anti-acne eg. Benzyl peroxide & Maintained efficacy with decreased skin irritation and sensitization. \\
\hline Anti-inflammatory eg. Hydrocortisone & Long lasting activity with reduction of skin allergic response and dermatomes. \\
\hline Antifungal eg. Fluconazole & Sustained release of actives \\
\hline $\begin{array}{l}\text { Antidandruff eg zinc pyrithione, selenium } \\
\text { sulphide }\end{array}$ & $\begin{array}{l}\text { Reduced unpleasant odor with lowered irritation with extended safety and } \\
\text { efficacy. }\end{array}$ \\
\hline Antipruitics & Extended and improved activity. \\
\hline $\begin{array}{l}\text { Skin de-pigmenting agents eg. } \\
\text { Hydroquinone }\end{array}$ & $\begin{array}{l}\text { Improved stabilization against oxidation with improved efficacy and aesthetic } \\
\text { appeal. }\end{array}$ \\
\hline Rubefacients & Prolonged activity with reduced irritancy greasiness and odor. \\
\hline
\end{tabular}

Korsmeyer developed a straight forward, empirical model, relating exponentially the drug unharness to the match on time $(\mathrm{t})$.

$$
\mathrm{Ft}=\mathrm{a} \cdot \mathrm{tn}
$$

Where a is constant incorporating structural and geometric characteristics of the drug dosage form, $\mathrm{n}$ is the release exponent, indicative of the drug release mechanism and function of $\mathrm{t}$ is Mt/Mœ (fractional release of drug) ${ }^{17}$.

\section{Hixson - Crowell Model:}

Hixson and Crowell (1931) recognized that the particle regular space is proportional to the root of its volume. They derived the equation :

$$
\mathrm{W} 01 / 3-\mathrm{Wt} 1 / 3=\mathrm{kt}
$$

Where $\mathrm{W} 0$ is that the initial quantity of drug within the pharamceuitical indefinite quantity type, $\mathrm{Wt}$. is that the remaining quantity of drug within the pharmaceutical indefinite quantity type at time $\mathrm{t}$ and $\mathrm{k}$ (kappa) could be a constant incorporating the surface volume relation. The equation describes the discharge from system wherever there's a amendment in expanse diameter of particles or tablets. To check the discharge dynamics, knowledge obtained from in vitro drug unharness studies were premeditated because the root of drug share remaining matrix versus time 17

\section{Spreadability Studies:}

One of the standards for a gel to fulfil the best qualities is that it ought to prossess sensible spredability. It's the term expressed to denote the extent of the world to that gel apace spread on application to the skin or affected half. The medical speciality effectualness of a formulation conjointly depends upon its spredability worth. Spredability is expressed in terms of your time in second taken by two slides to slide aloof from gel placed in between the slides beneath the direction of sure load. Lesser the time is taken for separation of two slides, higher the spredability. Spredability determined by glass slides and a engraving, that was provided by an easy machine at one end. By this method, spredability was measured on the premise of slip and drag characteristics of gels. A ground glass slide was fixed on this block. Associate way more than gel (about $1 \mathrm{gm}$ ) of varied formulations was placed on very cheap slide. The gel was then sandwiched between this slide and another glass slide having the dimension of fixed ground slide. Way more taken for separation of two slides. The very best plate was then subjected to drug of $20 \mathrm{gm}$, lesser spredability was then calculated by the following formula:-

$$
\mathrm{S}=\mathrm{M} \times \mathrm{L} / \mathrm{T}
$$

Where $\mathrm{S}$ is that the spredability, $\mathrm{M}$ is the burden among the pan (tied to the upper slide), $\mathrm{L}$ is that the length tormented by the glass slide, $\mathrm{T}$ represents the time taken to separate the slide absolutely from each other 11,15 . 


\section{MARKETED PRODUCT USING MICROSPONGE DELIVERY SYSTEM:}

\begin{tabular}{|c|c|c|}
\hline Product & Advantages & Manufacturer \\
\hline Retin-A-Micro & $\begin{array}{l}\text { Around } 0.1 \% \text { and } 0.04 \% \text { tretinoin entrapped in microsponge drug delivery } \\
\text { for topical treatment of acne vulgaris. This formulation uses patented } \\
\text { methyl methacrylate/ glycol dimethacrylate cross-polymer porous } \\
\text { microspheres (MICROSPONGE® System) to enable inclusion of the actives, } \\
\text { tretinoin, in an aqueous gel. }\end{array}$ & $\begin{array}{l}\text { Ortho-McNeil } \\
\text { Pharmaceutical, Inc. }\end{array}$ \\
\hline Carac Cream, $0.5 \%$ & $\begin{array}{l}\text { It consist of fluorouracil up-to } 0.5 \% \text {, with } 0.35 \% \text { being inclusive into a } \\
\text { patented microsponge that is composed of methylmethacrylateorglycol } \\
\text { dimethacrylatecross-polymeranddimethicone.Itisatopicalprescription } \\
\text { product for the treatment of actinickeratoses(AK)andusedonce-a-day, a } \\
\text { common pre-cancerous skin condition caused byover-exposure to the sun }\end{array}$ & $\begin{array}{l}\text { Dermik Laboratories, } \\
\text { Inc. }\end{array}$ \\
\hline Retinol cream & $\begin{array}{l}\text { The retinol molecule is kept in the microsponge system to protect the } \\
\text { potency of the vitamin A. This helps to enhance retinol dosage mean while } \\
\text { decreasing the possibility of irritation. Retinol is a topical vitamin A } \\
\text { derivative which helps to maintain the healthy skin, hair andmucous } \\
\text { membranes. }\end{array}$ & Biomedic, Inc. \\
\hline Biomedic, Inc. & $\begin{array}{l}\text { The Microsponge } ® \text { system uses the microscopic reservoirs that trap HQ } \\
\text { and retinol. This confers the skin with continuous exposure to } \\
\text { hydroquinone and retinol over time, which may reduce skin irritation. }\end{array}$ & Skin Medica Inc \\
\hline $\begin{array}{l}\text { Line Eliminator } \\
\text { DualRetinolFacial } \\
\text { Treatment }\end{array}$ & $\begin{array}{l}\text { Lightweight cream with a retinol in microsponge drug delivery system, it } \\
\text { delivers both immediate and time released of drug and having wrinkle- } \\
\text { fighting action. }\end{array}$ & Avon \\
\hline $\begin{array}{l}\text { Retinol } 15 \\
\text { Nightcream }\end{array}$ & $\begin{array}{l}\text { When we use Retinol } 15 \text { continuously in night will results in the visible } \\
\text { Diminishment of fine lines and wrinkles, observable improvement in the } \\
\text { skin discolorations due to aging and enhanced skin smoothness. }\end{array}$ & Sothys \\
\hline EpiQuin Micro & $\begin{array}{l}\text { This confers the skin with continuous exposure to hydroquinone and } \\
\text { retinol over time, which may reduce skin irritation. }\end{array}$ & Skin medica inc. \\
\hline $\begin{array}{l}\text { Sports cream RS } \\
\text { and XS }\end{array}$ & $\begin{array}{l}\text { Topical analgesic-anti-inflammatory and counterirritant actives used for } \\
\text { the management of musculoskeletal conditions in a Microsponge }{ }^{\circledR} \\
\text { Delivery System. }\end{array}$ & $\begin{array}{l}\text { Embil pharmaceutical } \\
\text { co.Ltd. }\end{array}$ \\
\hline
\end{tabular}

\section{CONCLUSION:}

Microsponge drug delivery holds sizable potential every in pharmaceutical additionally as cosmetics field. This strategies square measure engaging and create some ways to release bioactive agents with full efficiency, safety, improved stability, provided reduced aspect effects. Microsponges to boot provide nice advantages over different formulation with relevance agent and irritancy of drug. So contain various potential for developing novel formulations for the topical malady. Microsponge gel may give benefits of reduced facet effects, multiplied magnificence, increased formulation flexibility, and modify drug release. These microsponge gel square measure penetrate through skin by controlled release manner. Microsponges gel give patient compliance. This is often the benefit of the microsponge gel.

Acknowledgment: The author express thanks towards department of pharmaceutics, SGRS's college of pharmacy saswad for providing favorable timing for review this article.

\section{REFERANCED}

1] Won R. Method for delivering an active ingredient by controlled time release utilizing a novel delivery vehicle which can be prepared by a process utilizing the active ingredients as a porogen. Patent No. 4690825. US;1987.

2] Chowdary KP, Rao YS. Mucoadhesive microspheres for controlled drug delivery. Biol Pharm Bull2004; 27(11):1717-24.

3] Embil K, Nacht S. The Microsponge Delivery System (MDS): A topical delivery system with reduced irritancy incorporating multiple triggering mechanisms for the release of actives. J Microencapsul 1996; 13(5):575-88.

4] Nachit S, Kantz M. The microsponge: A novel topical programmable delivery system. Top Drug Deliv Syst1992; 42:299-325.

5] Chadawar V,Shaji J. Microsponge delivery system. Curr Drug Deliv 2007; 4(2):123-9.
6] Newton DW. Biotechnology frontier: Targeted drug delivery. US Pharmacist1991; 16:36-52.

7] Delattre L, Delneuville I. Biopharmaceutical aspects of the formulation of dermatological vehicles. J Eur Acad Dermatol Venereol 1995; 5:70-1.

8] Viral S, Jain H, Krishna J, Patel P. Microsponge drug delivery system: A review. Int J Res Pharm Sci2010; 1(2):212-8.

9] Yang L, ChuJ S, Fix JA. Colon-specific drug delivery: New approaches and in vitro/in vivo evaluation. Int J Pharm2002; 235(1-2):1-15.

10] Kydonieus AF, Berner B. Transdermal Delivery of Drugs. Vol. 261. Boca Raton: CRC Press; 1987. p.52-65.

11] Vyas SP, Khar RK. Targeted and Controlled Drug Delivery-Novel Carrier System. $1^{\text {st }}$ ed. New Delhi: CBS Publication; 2002. p.453-1.

12] Namrata J, Patel V,Mungekar S, Karpe M, Kadam V.Microsponge delivery system: An updated review current status and future prospects. World J Pharm Pharm Sci2007; 2(6):6463-85.

13] Aritomi H, Yamada K, Honda H, Koshi M. Development of sustained release formulation of chlorpheniramine maleate using powder coated microsponges prepared by dry impact blending method. J Pharm Sci Technol1996; 56(1):49-56.

14] D'souza JI, Masvekar RR, Pattekari PP,Pudi SR, More HN. Microspongic delivery of fluconazole for topical application. IndoJapanese Int Conf Adv Pharm Res Technol2004; 456:76-81.

15] Partibhan KG, Manivannan R. Krishnarajan D, Chandra S, Raj N. Microsponges role in Novel drug delivery. Int J Pharm Res Dev 2011; 3(4):117-1258.

16] Soni M, Saxena C, Soni P, Sharma DK. Microsponge: A versatile vesicular approach for Transdermal drug delivery system. J Global Pharm Tech2010; 2(3):154-64.

17] Aloorkar NH, Kulkarni AS, Ingale DJ, Patil RA. Microsponges as Innovative drug delivery systems. Int J pharm Sci Nonotechnol 2012; 5(1):143-151.

18] D'souza JI. The microsponge drug delivery system: For delivering an active ingredient by controlled time release. Pharmainfo. Net 2008; 6(3):47-62.

19] Patravale VB. Microsponges: A path-breaking cosmetic innovation. Emerging Technol Household Personal Care Today2008; 4:45-9.

20] Pradhan SK. Microsponges are as the versatile tool for drug 
delivery system. Int J Res Pharm Chem2011;40(1):196-201.

21] Kawashima Y,Niwa T, Takeuchi H, Hino T, Ito Y.Control of prolonged drug release and compression properties of ibuprofen microspheres with acrylic polymer, eudragit RS, by changing their intraparticle porosity [corrected]. Chem Pharm Bull (Tokyo)1992; 40(1):196-201.

22] Wester RC, Patel R, Nacht S, Leyden J, Melendres J, Maibach H. Controlled release of benzoyl peroxide from a porous microsphere polymeric system can reduce topical irritancy. J Am Acad Dermatol 1991; 24:720-6.

23] Santanu K, Sabyasachi M, Ghosh KA, Banerjee S. Micrsponge: A noval strategy for drug delivery system. J Pract Technol Res 2011; 5(2):243-28.

24] Brunton LL, Lazo JS, Parker KL. Goodman and Gilman's The Pharmacological Basis of Therapeutics. 11 $1^{\text {th }}$ ed., Vol. 2. New York: McGraw-Hill; 2006. p.1021-7.

25] Vikrant K, James S, Anne J and Manish SK. Microparticles: A novel approach to enhance the drug delivery. Int J Pharm Res Dev 2011; 3(8)170-83

26] Jain N, Sharma PK, Banik A. Recent advances in mirosponges drug delivery system. IJPSRR2011; 342:13-4.

27] Kilicarslan M, Baykara T. The effect of drug \& polymer ratio on the properties of the Verapamil hydrochloride loaded microspheres. Int JPharm2003; 252:99-109.

28] Mine 0, Erdal C. Design and evaluation of colon specific drug delivery system containing flurbiprofen microsponges. Int J of Pharm 2006; 318:103-117.

29] Martin A, Swarbrick J, Cammarrata A. In: Physical Pharmacy \& Physical Chemical Principles in Pharmaceutical Sciences. Vol.3. New Delhi, India: B. I. Waverly; 1991. p.527-36.

30] Vyas LK, Tapar KK, Laddha BH, Lahoti AO, Nema RK. Formulation and development of anti-blemish preparation using microsponge technology. J Chem Pharm Res2010; 2(5):562-71.

31] Ruckenstein E, Hong L. Concentrated emulsion polymerization pathway to hydrophobic and hydrophilic microsponge molecular reservoirs. Chem Mater1992; 4:1032-7.

32] Zaki Rizkalla CM, latif Aziz R, Soliman II. In vitro and in vivo evaluation of hydroxyzine hydrochloride microsponges for topical delivery. AAPS Pharm Sci Tech2011; 12(3):989-1001.

33] Shah VP. Determination of in-vitror elease from hydrocortisone creams. Int J Pharm1989; 53:53-9.

34] Christensen MS, Hargens CW rd, Nacht S, Gans EH. Viscoelastic properties of intact human skin: Instrumentation, hydration effects, and the contribution of the stratum corneum. J Invest Dermatol 1977; 69(3):282-6.

35] Sato T, Kanke M, Schroeder HG, DeLuca PP. Porous biodegradable microspheres for controlled drug delivery. I. Assessment of processing

conditionsandsolventremovaltechniques.PharmRes1988; 5(1):2130.

36] Guyot M, Fawaz F. Microspheres preparation and physical characteristics. Int J Pharm1998; 175:61-74.

37] Kaity S, Maiti S, Ghosh AK, Pal D, Ghosh A, Banerjee S. Microsponges: A novel strategy for drug delivery system. J Adv Pharm Technol Res 2010; 1(3):283-90.

38] Roaa AN, Hussein AA. Preparation and evaluation of meloxicam microsponges as transdermal delivery system. Iraqi J Pharm Sci 2014; 23(2):62-74.

39] Anilkumar JS, Mano B, Sawant SS. Development and evaluation of fenoprofen microsponges and its colonic delivery using natural polysaccharides.IntPublAmJPharmSciNanotechnol2014;1(1):2742.

40] Markhand M, Amish P,Viral HS, Upadhyay U. Formulation and inintro evaluation of release microsponge gel for topical delivery of clotrimazole. Int J Adv Pharm2012; 2:93-101.

41] Makwana R, Patel H, Petal V, Photostability enhancement of miconazole nitrate by microsponge formulation. Int J Curr Trends Pharm Res2014; 2(3):437-58.

EmanueleAD,DinarvandR.Preparationcharacterizationand drug release from thermo responsive microspheres. Int J Pharm 1995 118:237-45.

42] Shah V, Jain H, Jethva K, Patel P. Microsponge drug delivery an overview. Int J Res Pharm Sci2010; 1(2):212-8.

43] HarinathN,D’SouzaIJ.Topicalanti-inflammatorygelsoffluocinolone acetonide entrapped in eudragit based microsponge delivery system. Res J Pharm Technol2008; 1(4):72-9.

44] Mohan KV, Veena NM, Manjula BP. Formulation and evaluation of microsponges for topical drug delivery of Mupirocin. Int J Pharm Technol Res2013; 5(2):1434-40.

45] P yadav, S Nanda. Department and evaluation of some microsponge loaded medicated topical formulation of acyclovir. Int J Pharm Sci Res 2014; 5:1395-410 .

46] Rajurkar VG, Tambe AB, Deshmukh VK. Topical anti-inflammatory gels of Naproxen entrapped in eudragit based microsponge delivery system. Adv Chem Engg2015; 5(2):251-8.

47] Chandramoul Y,Firoz S, Rajalakshmi R, Vikram A, Yasmeen RB, Chakravarthi RN. Preparation and evaluation of microsponge loaded controlled release topical gel of acyclovir sodium. Int J Biopharm 2012; 3(2):96-102.

48] Panday P, Shukla N, Sisodiya D, Jain V, Mahajan SC. Design and characterization of microsponge loaded controlled releaseepicutaneous gel of lornoxicam. Appl Med Res2015; 3(2):16-20.

49] Wakiyama N, Juni K, Nakano M. Preparation and evaluation invitro of polylactic acid microspheres containing local anesthetics. Chem Pharm Bull (Tokyo)1981; 29(11):3363-8.

50] Khopade AJ, Jain S, Jain NK. The microsponge. Eastern Pharmacist 1996; 6(3):49-53.

51] Jelvehgari M, Siahi-Shadbad MR, Azarmi S, Martin GP, Nokhodchi A. The microsponge delivery system of benzoyl peroxide: Preparation, characterizationandreleasestudies.IntJPharm2006; 308(1-2):124-32.

52] Amrutiya N, Bajaj A, Madan M. Development of microsponges for topical delivery of mupirocin.AAPS PharmSciTech 2009; 10(2):402-9.

53] Fincham AE, Kamik KA. Patient counseling and derm therapy. US Pharm1994; 19:56-7.

54] Embil VP.OTC External analgesic cream, topical analgesic-antiinflammation, counterirritant utilizing the microsponge delivery system (MDS) for controlled release of actives Patent Application No: 0101058;UK-2000.

55] Comoglu T, Gönül N, Baykara T. Preparation and invitro evaluation of modified release ketoprofen microsponges. Farmaco 2003; 58(2):101-6

56] Hibab A, Shaimaa MB. Microsponge as promising vehicle for drug deliver and targeting preparation, characterization and application. Afr J Pharm Pharm2013; 7(17):873-81.

57] Jain V,Singh R. Dicyclomine loaded eudragit based microsponge with potential for colonic delivery: Preparation and characterization. Trop J Pharm Res2010; 9(1):67-72.

58] Jain V,Singh R. Development and characterization of eudragit RS100 loaded microsponges and its colonic delivery using natural polysaccharides. Acta Pol Pharm 2010; 67(4):407-15.

59] Mishra KM, Shikhri M, Sharma R, Goojar MP. Optimization, formulation development and characterization of Eudragit RS 100 loaded microsponges and subsequent colonic delivery. Int J Drug Discov Herbal Res2011; 1(1):8-13.

60] Jain NK, Sharma SN. A Textbook of Professional Pharmacy. $4^{\text {th }}$ ed. New Delhi: Vallabh Prakashan; 2006. p.257-72.

61] Shyam SM, Vedavathi T. Novel approach microsponge drug delivery system. Int J Pharm Sci Res2012; 1(3):967-80.

62] Srivastava R, Pathak K. Microsponges: A futuristic approach for oral drug delivery. Expert Opin Drug Deliv2012; 9(7):863-78.

63] Rossi S, Buckley N. Australian Medicines Handbook. Adelaide: Australian Medicines Handbook Pvt., Ltd.; 2006. p.3572-9.

64] Baselt R. Disposition of Toxic Drugs and Chemicals in Man. $8^{\text {the }}$. Foster City: Biomedical Publications; 2008. p.29-31.

65] Gangadharappa HV, Gupta NV, Prasad MS, Shivakumar HG. Current trends in microsponge drug delivery system. Curr Drug Deliv 2013; 10(4):453-65.

66] Trotta F, Cavalli R, Tumiatti W. Cyclodextrin-based nanosponges for drug delivery. J Incl Phenom Macrocycl Chem2006; 56:209-13.

67] Hu SH, Liu TY, Liu DM, Chen SY.Nano-ferrosponges for controlled drug release. J Control Release 2007; 121:181-9.

68] Li NH, Benson JR, Kitagawa N. Polymeric microbeads and method of preparation. International Publication No. W01995033553; 2003.

69] Lee JB, Hong J, Bonner DK, Poon Z, Hammond PT. Self-assembled RNA interference microsponges for efficient siRNA delivery. Nat Mater2012; 11(4):316-22. 